\title{
Prevalence of G6PD deficiency and Plasmodium falciparum parasites in asymptomatic school children living in southern Ghana
}

\author{
Linda Eva Amoah ${ }^{1 *}$, Akua Opong ${ }^{1}$, Ruth Ayanful-Torgby ${ }^{1,2}$, Joana Abankwa ${ }^{1}$ and Festus K. Acquah
}

\begin{abstract}
Background: Glucose-6-phosphate dehydrogenase (G6PD) deficiency is an X-linked genetic disorder that results in impaired enzyme activity. Although G6PD deficiency is globally distributed it is more prevalent in malaria-endemic countries. Several mutations have been identified in the G6PD gene, which alter enzyme activity. The G6PD genotype predominantly found in sub-Saharan Africa is the G6PDB (G6PD $376 \mathrm{~A})$ with $\left(\mathrm{G} 6 \mathrm{PD}_{376 \mathrm{G}}\right)$ and G6PDA- $\left(\mathrm{G} \mathrm{PD}_{3766 / 202 \mathrm{~A}}\right.$, $\mathrm{G} \mathrm{PD}_{376 \mathrm{G} / 542 T}, \mathrm{G}_{\mathrm{P}} \mathrm{PD} \mathrm{D}_{376 \mathrm{G} / 680 \mathrm{~T}}$ and $\mathrm{G} 6 \mathrm{PD}_{376 \mathrm{G} / 968 \mathrm{C}}$ ) occurring at lower frequencies.
\end{abstract}

Aim: The aim of this study was to identify the prevalence of G6PD deficiency and asymptomatic Plasmodium falciparum carriage in children living in southern Ghana and determine whether G6PD deficiency influences asymptomatic carriage of $P$. falciparum parasites.

Methods: Blood samples were obtained once a month from 170 healthy Ghanaian school children aged between 5 and 12 years from Basic schools in two communities Obom and Abura with similar rainfall patterns and malaria peak seasons. G6PD enzyme activity was assessed using the qualitative G6PD RDT kit (AccessBIO). G6PD genotyping and asymptomatic parasite carriage was determined by PCR followed by restriction fragment length polymorphism (RFLP) of DNA extracted from dried blood spots.

Results: The only sub-Saharan G6PD A- allele detected was the A376G/G202A found in $12.4 \%$ (21/170), of the children and distributed as $4.1 \%$ (7/170) A-, $1.8 \%$ (3/170) A-/A- homozygous deficient males and females and $6.5 \%$ (11/170) A/A- and B/A- heterozygous deficient females. Phenotypically, $10.6 \%$ (15/142) of the children were G6PD deficient. The asymptomatic carriage of P. falciparum by PCR was 50, 29.4, 38.2 and $38.8 \%$ over the months of February through May 2015, respectively, and 28.8, 22.4, 25.9 and $5.9 \%$ by microscopy during the same periods.

Conclusions: G6PD deficiency was significantly associated with a lowered risk of PCR-estimated asymptomatic P. falciparum carriage in children during the off peak malaria season in Southern Ghana.

Keywords: Malaria, G6PD, Plasmodium falciparum, Primaquine, Genotyping, RFLP, ELISA

\section{Background}

Malaria is a deadly disease caused by five Plasmodium species with Plasmodium falciparum being the most

\footnotetext{
*Correspondence: lamoah@noguchi.ug.edu.gh

${ }^{1}$ Immunology Department, Noguchi Memorial Institute for Medical Research, College of Health Sciences, University of Ghana, Legon, Accra, Ghana

Full list of author information is available at the end of the article
}

lethal. Plasmodium falciparum caused an estimated 438,000 deaths globally in 2015 [1]. The heaviest burden of malaria, according to the World Health Organization (WHO), is in Africa where an estimated 395,000 malaria deaths was recorded in 2015 [1].

G6PD deficiency (G6PDd) is one of the most common human genetic enzyme defects [2], affecting over 400 million people. Although this enzymopathy is globally distributed, it is more prevalent in the tropics and 
sub-tropics, especially in malaria-prone countries [3]. This $\mathrm{X}$-linked genetic condition is characterized by reduced G6PD enzyme activity, which can remain asymptomatic. Red blood cells obtain reduced glutathione (GSH) solely from the G6PD/reduced nicotinamide adenine dinucleotide phosphate (NADH) pathway. The deficiency makes red cells more susceptible to oxidative haemolysis that can be triggered by certain drugs, such as primaquine (PQ) and other 8-amino quinolone drugs [4]. Glucose-6-phosphate dehydrogenase (G6PD) and a number of other human genetic traits including sickle cell anaemia and related haemoglobinopathies are predominantly found in populations living in malaria endemic countries and have been suggested to provide the host protection from severe forms of malaria [5-8] and asymptomatic malaria [9]. A number of genetic traits that protect the host against severe forms of malaria have recently been found to promote the development of the sexual transmissible stages of the parasite, and individuals with these traits serve as reservoirs for malaria transmission [10] or alter the acquisition of anti-parasite antibodies [11].

G6PD deficiency can be determined using a number of approaches, including, quantitative tests, which measure precise enzyme activity, qualitative tests which classify enzyme activity as normal or deficient and genetic tests, which identify gene mutations [12-19].

Over 400 G6PD variants have been identified [4] and the polymorphisms are predominantly defined to specific geographic locations [20]. In sub-Saharan Africa, the predominant G6PD variants are B, A and A-, with frequencies greater than $1 \%$. The G6PD B variant has the 376A cDNA sequence and is classified as possessing normal enzyme activity. The non-deficient G6PD A variant has been shown to possess about $85 \%$ of the activity of the normal enzyme and is classified as possessing normal activity carries a cDNA mutation A376G, which translates into amino acid N126D. The sub-Saharan G6PD A- variants carry the G6PD A backbone with an additional single mutation, the most common A-variant has the A376G/G202A cDNA mutation. G6PD A- been suggested to possess $10 \%$ of normal enzyme activity in their red blood cells though their white blood cells maintain $100 \%$ normal enzyme activity [21] Additional A- variants peculiar to sub-Saharan Africa include the A376G/ A543T, A376G/G680T and A376G/T968C [19].

Global efforts to achieve malaria elimination have lead the WHO to recommend PQ, the only WHO certified anti-gametocyte drug, to be incorporated into malaria treatment regimens in selected countries to reduce malaria transmission [22]. Although low-dose PQ has been found to be safe for use in G6PDd individuals [23, 24 , a number of other reports have found PQ to cause dangerous side effects in G6PDd individuals [25, 26] making it necessary to monitor the prevalence of G6PD as well as determine possible effects this trait has on malaria in Ghanaians.

\section{Methods \\ Study site and sampling}

Abura Dunkwa, also known as Abura, is the district capital for Abura-Asebu-Kwamankese district of the Central Region with a rural population of 31,768 for children under 14 years of age [27]. Obom is in the Ga south municipality of the Greater Accra Region with a rural population of 22,368 for children under 14 years of age [28]. Abura (Cape Coast) is an area of seasonal malaria transmission and Obom (Accra) is an area of perennial malaria transmission, both of which have the peak malaria season between June to August. Inhabitants of these regions have different ethnicities. Although a total of 200 school children aged from six through 12 years were recruited for this study, 30 missed at least one of the four sampling days. Out of the 170 children, 150 were randomly selected for phenotypic analysis of G6PD enzyme activity.

\section{Microscopic estimation of malaria parasite}

Thick and thin blood smears as well as dried filter paper blood spots (DBS) were each made from a drop $(\sim 50 \mu \mathrm{l})$ of finger-prick blood. The slides were air-dried, the thin smear fixed in methanol and both smears stained with $10 \%$ Giemsa for $15 \mathrm{~min}$. The stained slides were subsequently air-dried and viewed under 100X oil immersion microscope. Two independent microscopists read the slides. Parasitaemia was determined as the $\%$ of malaria parasites observed per 200 white blood cells (WBCs).

\section{DNA extraction from dried blood spots}

DNA and antibodies were extracted from the DBS [29]. Briefly, two $3 \mathrm{~mm}$ disks were punched from the filter paper blood blots into a $2 \mathrm{ml}$ microcentrifuge tube. The tube was then filled with $1120 \mu \mathrm{l}$ of $0.5 \%$ saponin and left to shake overnight at room temperature. The saponin supernatant containing the eluted antibodies was decanted and saved for the ELISAs. The disks were washed for $30 \mathrm{~min}$ in ice cold PBS at $4{ }^{\circ} \mathrm{C}$. The wash solution was decanted and the tubes filled with $150 \mu \mathrm{l}$ of $6 \%$ chelex in PBS. The tubes were then heated at $\sim 99{ }^{\circ} \mathrm{C}$ for $30 \mathrm{~min}$ with a quick vortex and centrifuge every $10 \mathrm{~min}$. The heat extracted DNA was aliquoted into a new tube and either used immediately or stored at $4{ }^{\circ} \mathrm{C}$ for use within 2 weeks.

\section{Plasmodium falciparum genotyping}

MSP2 and/or GLURP genotyping was performed on the extracted gDNA to simultaneously determine parasite 
prevalence and diversity. The WHO malaria parasite genotyping protocol (23) was followed with slight modifications. PCR reactions were carried out in $15 \mu \mathrm{l}$ volumes for both the primary and nested reactions. Briefly the $200 \mathrm{nM}$ M2-0F and M2-0R primers were used to amplify $4 \mu \mathrm{l}$ of extracted DNA using One Taq polymerase (NEB). The nested reaction was carried out using $1 \mu \mathrm{l}$ of the primary PCR product with $200 \mathrm{nM}$ each of the combination of S1Fw/N5rev for the 3D7 type alleles or S1Fw/M5rev for the FC27 type alleles. For GLURP, the G-F3 and G-F4 primer pair was used for the outer PCR reaction and the G-NF and G-F4 primer pair used for the nested inner reaction. All the PCR fragments and the digested products were viewed under UV after resolving on a $2 \%$ agarose gel containing $0.5 \mu \mathrm{g} / \mathrm{ml}$ ethidium bromide.

\section{G6PD enzyme activity}

Rapid detection of enzyme activity was determined using the G6PD rapid diagnostic test kits (Access BIO, USA) according to manufacturer's instructions. Briefly, the finger was pricked with a lancet provided in the kit and the blood spotted on to the sample pad of the test cassette. Two drops of buffer was applied to the sample pad and after $15 \mathrm{~min}$ the colour of the sample pad was noted. A purple membrane indicated normal enzyme activity whilst a white membrane indicated enzyme deficiency.

\section{G6PD genotyping}

PCR was performed on DNA extracted from the DBS as previously reported [30]. The A376G polymorphism was analysed in each DNA sample using PCR followed by digestion with 1 unit of FOKI restriction enzyme under manufacturer-recommended conditions in a thermal cycler. Only those samples that were $376 \mathrm{G}$ and thus produced a digested product were further analysed for three other sub-Saharan African cDNA mutations, G202A, G680T and T968C by similar restriction fragment length polymorphism. The G202A PCR amplicon was digested with NlaIII restriction enzyme, the G680T amplicon was digested with BstNI restriction enzyme and the T968C amplicon digested with NciI restriction enzyme for $1 \mathrm{~h}$ at $37{ }^{\circ} \mathrm{C}$. All the PCR fragments and the digested products were viewed under UV after resolving on a $2 \%$ agarose gel containing $0.5 \mu \mathrm{g} / \mathrm{ml}$ ethidium bromide.

\section{Statistical analysis}

Microsoft excel and SPSS 22.0 (IBM Corp) were used for all data analysis and to generate the frequency and cross tabulation tables. Frequency of parasite carriage was calculated as the (Additional file 1) sum of the number of times a child was observed to be parasite positive over the four time points. SPSS linear regression was used with model fit analysis to identify significant correlations between frequency of parasite carriage estimated by microscopy and PCR (dependent variables) and G6PD genotype and phenotype (independent variables). The relationship between G6PD genotype and phenotype was obtained using crosstabs descriptive statistics. Statistical significance was defined as $p$ value $\leq 0.05$.

\section{Results \\ Study site}

The study utilized blood samples collected from a longitudinal survey of children living in southern Ghana (Fig. 1) from February through May 2015. Two hundred study participants were recruited but the data presented analysed samples from 170 children who were available for all four blood collection visits. The mean age of the children was $9.12 \pm 0.13$ however $45 \%$ of the children were either nine or 10 years old. Fifty-four percent $(92 / 170)$ of the children were female (Table 1$)$, however the ratio was slightly increased to $56 \%(80 / 142)$ in the subset used for the G6PD phenotype analysis. None of the children were symptomatic for malaria during any of the sampling visits.

\section{G6PD phenotype}

Out of the 150 children sampled with the G6PD RDT, 8 gave invalid results. From the 142 valid test results, $10.6 \%$ (15/142) were branded G6PD deficient, with boys representing $47 \%(7 / 15)$ of the total G6PDd population (Table 1). Ninety-one percent and $85 \%$ of boys and girls respectively carried normal G6PD genotypes while 89 and $90 \%$ of boys and girls were characterized as possessing normal G6PD enzyme activity (Table 1).

\section{G6PD genotype}

The only G6PD A- genotype identified was A376G/ G202A, which was identified in seven hemizygous G6PDd (A-) males, 11 heterozygous G6PDd females (B/A-, A/A) and three homozygous G6PDd (A-/A-) females, representing 4.1, 6.5 and $1.8 \%$ of the 170 school children respectively (Table 1 ).

\section{Microscopic and PCR estimation of parasite carriage}

The monthly $P$. falciparum prevalence estimated by PCR for February through May 2015 was 50 \% (85/170), 29.4\% (50/170), $38.2 \%(65 / 170)$ and $38.8 \%$ (66/170) (Fig. 2a). PCR parasite genotyping identified $20 \%(34 / 170)$ of the children to have remained parasite free during all the four visits, $29.4 \%(50 / 170)$ to have been parasite positive at least once during the four visits, $30.6 \%(52 / 170)$ to have had parasites on two visits, $14.7 \%(25 / 170)$ to be parasite positive on three visits and $5.3 \%(9 / 170)$ to have persistently carried parasites during each monthly visit (Fig. 1b). 


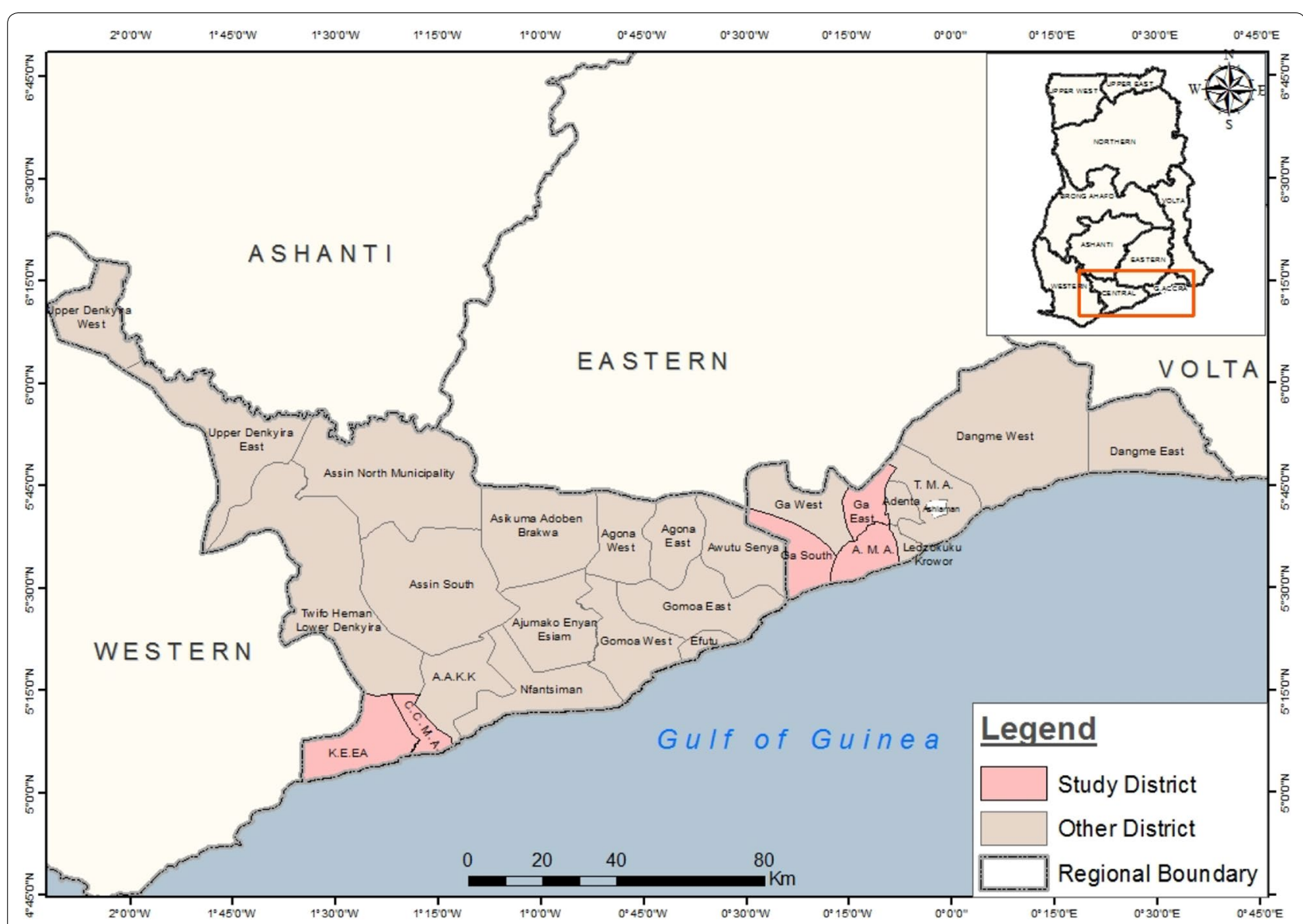

Fig. 1 Map showing the location of study sites. Children were selected from four schools, two each in Obom in the Ga South municipality of the Greater Accra Region and Abura, in the Cape Coast municipality of the Central Region. Both sites lie on the southern coast of Ghana

Table 1 Distribution of G6PD genotype and phenotype by sex

\begin{tabular}{llll}
\hline & Deficient (P) & Deficient (G) & $\begin{array}{l}\text { Heterozygous } \\
\text { deficient (G) }\end{array}$ \\
\hline Female & $5.6 \%(8 / 142)$ & $1.8 \%(3 / 170)$ & $6.5 \%(11 / 170)$ \\
Male & $4.9 \%(7 / 142)$ & $4.1 \%(7 / 170)$ & $0 \%(0 / 170)$ \\
\hline
\end{tabular}

Deficient (P), deficient G6PD enzyme activity; Normal (P), normal G6PD enzyme activity; Deficient (G), deficient genotype ( $\mathrm{A}$ - and $\mathrm{A}-/ \mathrm{A}$-); Heterozygous deficient $(G)$, female heterozygous deficient (A/A- and B/A-); Normal (G), normal genotype $(A, B, A / A, A / B$ and $B / B)$

Microscopy estimated $P$. falciparum prevalence for February through May 2015 as 28.8 \% (49/170), $22.4 \%$ (38/170), $25.9 \%$ (44/170) and $5.9 \%$ (10/170) (Fig. 2a). The proportion of children who remained parasite free by microscopy during all the four visits was $50.6 \%(86 / 170)$, those that were positive at least once during the four visits was $26.5 \%$ (45/170). The proportion of children who were parasite positive at two and three visits was $12.9 \%$ $(22 / 170)$ and $10 \%(17 / 170)$ respectively. No child was identified as harbouring microscopic parasites at each of the four visits (Fig. 2b).

PCR detected a much higher prevalence of parasites than microscopy during each of the four survey points. Sub-microscopic P. falciparum carriage was estimated as the number of children with PCR detectable parasites who were classified as parasite negative by microscopy. Due to the much higher prevalence of parasites detected by PCR, sub-microscopic parasite carriage by the children during the survey period was generally high, especially in May when microscopic parasite carriage was the lowest.

\section{G6PD status and asymptomatic Plasmodium falciparum carriage}

Neither sub-microscopic parasite carriage nor microscopic parasite carriage over the 4 months was significantly associated with G6PD genotype and phenotype when tested with the model fit linear regression model $(p>0.05)$. However, parasite carriage estimated by PCR was significantly associated G6PD genotype but not 

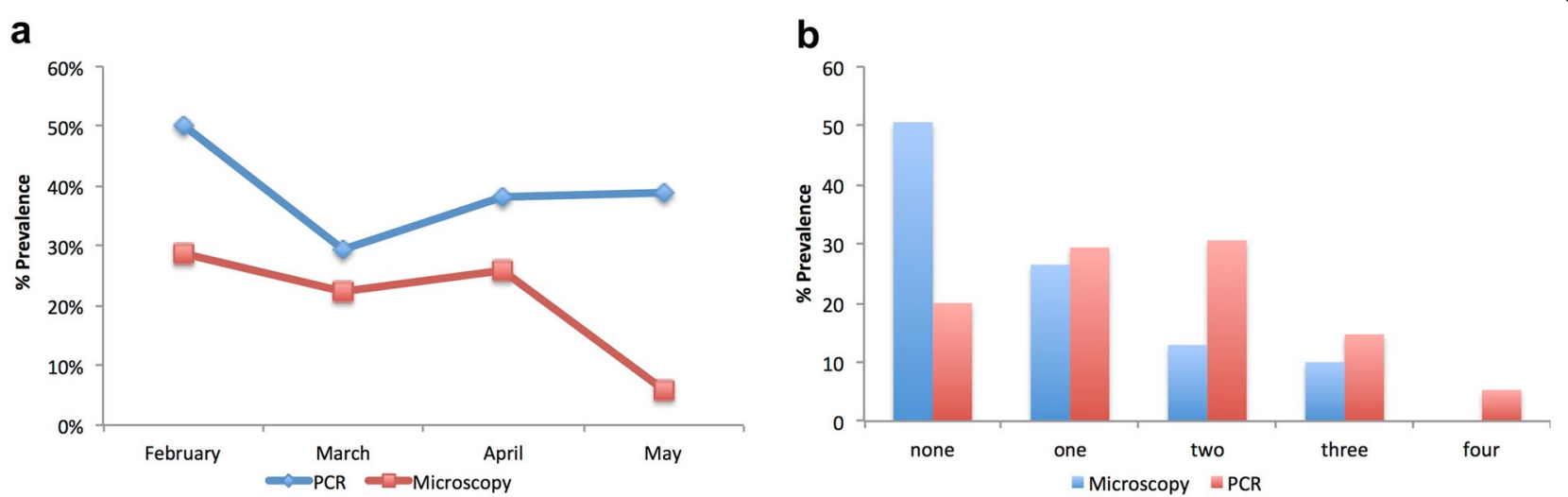

Fig. 2 a $P$. falciparum parasite prevalence estimated by microscopy and PCR. Giemsa stained thick blood smears from samples collected monthly from a set of children were read and used to estimate parasite prevalence. PCR analysis of gDNA extracted from these same samples was also used to estimate parasite prevalence. $\mathbf{b}$ The number of times any particular child was classified as P. falciparum positive by either microscopy or PCR over the 4 month period was documented

G6PD phenotype $(\mathrm{p}<0.05)$ (Table 3$)$. There was a trend of a child having a lower tendency to carry malaria parasites at all four sampling times with both the G6PDd and the G6PDn children (Fig. 3a-d).

\section{Comparison of G6PDd prevalence by phenotypic RDT and PCR genotyping}

Less than $5 \%$ of children with normal G6PD genotypes were found to possess normal enzyme activity, however almost $50 \%$ (44-56\%) of the hemi and homozygous deficient as well as the heterozygous deficient G6PD genotypes were found to possess normal enzyme activity using the qualitative G6PD RDT kits (Table 2).

\section{Discussion}

In order to identify any possible influence of G6PD deficiency on asymptomatic malaria carriage, this study was conducted over the off peak malaria season, from February through to May 2015, when symptomatic $P$. falciparum carriage is low. Some previous studies have identified relationships between G6PD deficiency and protection from severe malaria $[2,31]$ as well as asymptomatic status [9]. In Ghana, however, most studies have concentrating on pregnant women due to the national sulfadoxine-pyrimethamine intermittent preventative treatment in pregnant women (SP-IPTp) policy [32-35]. Very few studies have focused on asymptomatic malaria patients or simultaneously carried out genotypic and phenotypic analysis of G6PD on the same individual [30, 36] as such, this study set out to find a possible correlation of G6PD with asymptomatic malaria in Ghana.

Asymptomatic parasite carriage estimated by PCR was very high, averaging about $40 \%$ over the 4 months of the study (Fig. 2a). An average of $26 \%$ of the children were identified as asymptomatic for malaria by microscopy for the first 2 months (February to April). The asymptomatic status of the children who tested positive for P. falciparum was confirmed by the fact that none of the children had a fever of $37.5{ }^{\circ} \mathrm{C}$ and above or any other physical symptoms of malaria during any of the four blood draws. Such high levels of asymptomatic P. falciparum carriage suggests that the children have developed immunity to malaria and serve as reservoirs for the parasite, which is likely to be a channel for intense malaria transmission when the mosquitoes start breeding during the rainy season.

The high prevalence (23\%) of samples, of children who were found to be parasite positive by microscopy more than once during the 4 monthly visits (Fig. 2b) could explain the sustained transmission of malaria immediately after the rainy season begins as there is a possible continuous production of gametocytes from these asexual parasites. The superiority of PCR over microscopy, the gold standard for the detection and diagnosis of malaria was confirmed in this study as the number of children found to be $P$. falciparum parasite free over the entire study period reduced from $50.6 \%$ as observed by microscopy to $20 \%$ after PCR analysis (Fig. 2b).

This study identified only the 376G/202A G6PDA- variant, which has so far been the only G6PD variant identified in Ghana $[9,30,36]$. The prevalence of G6PDd, of \% (7/170) A- males and $1.8 \%$ (3/170) A-/A-females identified in the study population (Table 1 ) is lower than previously published for Ghana [30]. The difference could be due to the use of a study population inhabiting the southern coast of Ghana as a previous report has shown that the prevalence of G6PDd in both males and females is higher in Kintampo, which is to the north of Kumasi than in Kumasi, which is in the middle belt of Ghana 

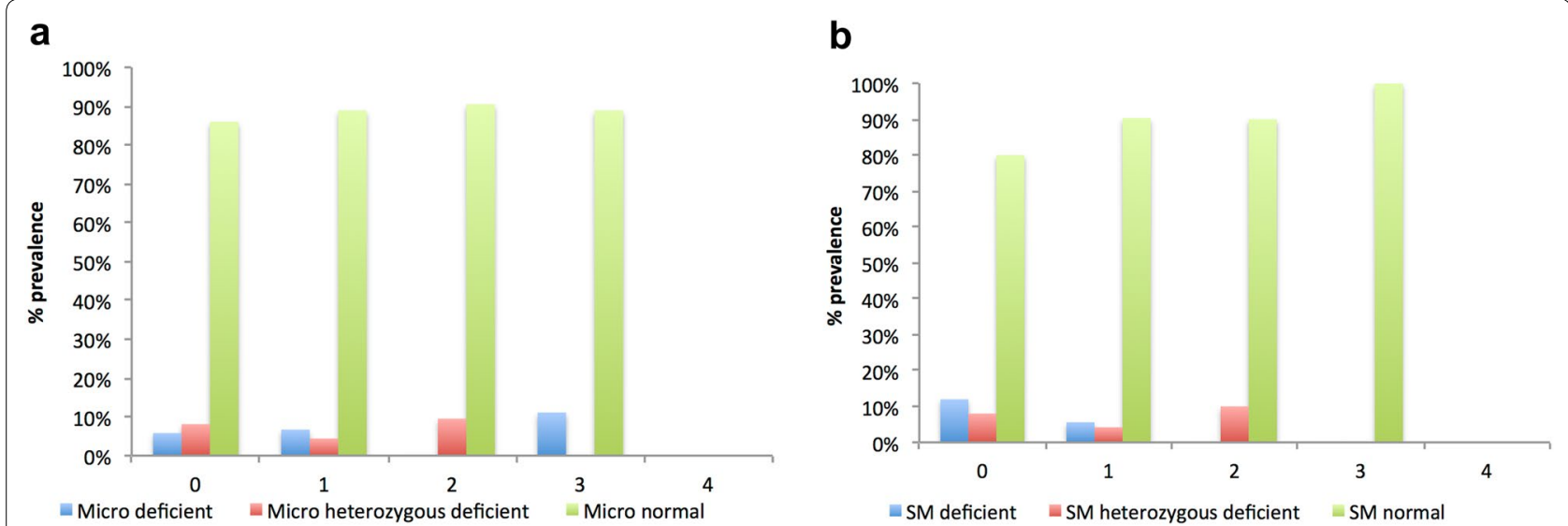

Fig. 3 Frequency of P. falciparum carriage in G6PD normal and deficient children. Cumulative incidence of observed parasite carriage (microscopic and sub microscopic) in children classified as either G6PD normal or deficient by genotyping or RDT kit phenotypng over the 4 monthly visits. Frequency of microscopic (a) and sub microscopic parasite (b) parasite carriage within the three G6PD genotype groups, deficient (A- and A-/A-); Heterozygous deficient (A/A- or B/A-) and Normal (A, B, A/A, A/B, B/B)

Table 2 Analysis of G6PD genotype and phenotype

\begin{tabular}{lll}
\hline & Deficient (P) & Normal (P) \\
\hline Deficient (G) & $55.6 \%(5 / 9)$ & $44.4 \%(4 / 9)$ \\
Heterozygous deficient (G) & $44.4 \%(4 / 9)$ & $55.6 \%(5 / 9)$ \\
Normal (G) & $4.8 \%(6 / 124)$ & $95.2 \%(118 / 124)$ \\
\hline
\end{tabular}

Deficient (P), deficient RDT read out; Normal (P), normal RDT read out; Deficient (G), deficient gene variant (A- and A-/A-); Heterozygous deficient (G), female with a heterozygous genotype (A/A- or B/A-); Normal (G), gene variants known to posses normal g6pd enzyme activity $(A, B, A / A, A / B, B / B)$. All the samples were analysed for G6PD enzyme activity using the qualitative CareStart ${ }^{\text {TM }}$ G6PD RDT kits as well as the presence of the sub Saharan African G6PD gene variants

[30]. Forty four percent of G6PD A- and A-/A- children possed normal enzyme activity (Table 2) which is higher than that perviously reported in a study conducted in six African countrie including Ghana, where $10 \%$ of G6PD A- males and 24\% G6PD A-/A- females possessed normal enzyme activity [30].

A previous study conducted in Ghana found G6PDd children to be about 1.5 times more likely to be parasitaemic based on microscopic evaluation of thin and thick blood films than non-deficient children [37], suggesting that the G6PD deficiency was associated with marginal susceptibility to clinical malaria in a child under 5 years of age. This study involved slightly older children who did not display such an association of G6PDd and malaria. PCR detectable parasite carriage but not parasite carriage by microscopy was significantly $(\mathrm{p}=0.038)$ associated with the G6PD normal genotype (Table 3, Additional file 1), which slightly supports previous reports that suggests the G6PD trait offers some protection from malaria [38, 39]. G6PD deficient children also had a lower tendency to carry sub-microscopic $P$. falciparum parasites more than once during the 4 month period (Fig. 3a) although some G6PDd deficient children carried microscopically detectable parasites three out of the four sample visits (Fig. 3b).

Genotyping G6PD by RFLP analysis identifies only the known G6PD genotypes, leaving the possibility of identifying novel mutations, which could possibly impact enzyme activity (28). A sample can be misclassified as normal due to the absence of particular mutations

Table 3 Summary of linear regression analysis

\begin{tabular}{lllllll}
\hline Model fit & $\begin{array}{l}\text { Standardized coefficients } \\
\text { Beta (PCR) }\end{array}$ & Sig $^{\mathbf{a}}$. (PCR) & $\begin{array}{l}\text { Standardized coefficients }^{\mathbf{b}} \\
\text { Beta (Micro) }\end{array}$ & Sig $^{\mathbf{b}}$. (Micro) & $\begin{array}{l}\text { Standardized coefficients }^{\mathbf{c}} \\
\text { Beta (SM) }\end{array}$ & Sig $^{\mathbf{c}}$. (SM) \\
\hline (Constant) & & 0.032 & & 0.009 & & 0.103 \\
G6PD (P) & -0.03 & 0.707 & -0.011 & 0.89 & 0.126 & 0.112 \\
G6PD (G) & 0.166 & 0.038 & 0.02 & 0.8 & 0.133 & 0.093 \\
\hline
\end{tabular}

G6PD (P), G6PD phenotype; G6PD (G), G6PD genotype

a Dependent variable: frequency of $P C R$ detectable parasite carriage

${ }^{b}$ Dependent variable: frequency of Microscopic parasite carriage

c Dependent variable: frequency of sub microscopic parasite carriage 
characterized despite carrying mutations that were not analysed. The six children who did not carry an A- allele but were identified as having reduced G6PD enzyme activity (Table 2) could have possessed other deficiency causing mutations that were not characterized possibly because they have not been assigned a genotype [40]. A study conducted in the Gambia on 1437 children between 5 and 14 years found half (50\%) the study population to carry the G6PD A376G (B) variant and $39 \%$ to carry mutations that have not been assigned a genotype [41]. Heterozygous G6PD deficient females are able to randomly inactivate one of their two X-chromosomes and as such exhibit either normal or deficient G6PD enzyme activity $[42,43]$. As such a little over half (5/9) of the heterozygous deficient children exhibited normal G6PD enzyme activity.

The CareStart ${ }^{\mathrm{TM}}$ G6PD RDT classified $44.4 \%$ (4/9) of A- and A-/A- deficient children as normal (to possess normal G6PD enzyme activity). This could be due to inaccuracies and the level of subjectivity of the RDT kit readout $[13,14,16,44]$. Some studies have found people with the same G6PD cDNA mutation to exhibit different enzyme activities due to possible differences in the G6PD acetylator in the deficient persons [45] as well as the possible contribution of a number of superimposed genetic deficiencies [46] and blood sugar levels [47].

\section{Limitations}

Genetic analysis of G6PD deficiency was carried out using RFLP and specifically determined common subSaharan African G6PD genotypes. As such other deficiency causing mutations which were not analysed could have been present in the study population. Additional characterization of red blood cells were not performed although certain red blood cell conditions such as anaemia, which causes a reduction in the volume of older G6PDd RBC's and an increase in reticulocytes, could result in anaemic G6PDd child exhibiting near normal G6PD enzyme activity [48]. A disadvantage to the rapid qualitative CareStart ${ }^{\mathrm{TM}}$ G6PD RDT kit used for G6PD phenotypic analysis is that read out can be subjective and a few sample results could have been misinterpreted.

\section{Conclusions}

Asymptomatic $P$. falciparum carriage over the off peak malaria season of 30 to $50 \%$ could likely be a driving force to sustained malaria transmission over the off peak season. Twelve percent of the school children carried genetically deficient G6PD genes and $11 \%$ were identified as having deficient G6PD enzyme activity. The frequency of parasite carriage estimated by PCR was significantly associated with G6PD phenotype. A similar study should be conducted in the peak malaria season to determine the consequences asymptomatic P. falciparum carriage has on malaria transmission as well as identify association between G6PD and malaria in these same children during the peak season.

\section{Additional file}

Additional file 1. Additional tables.

\section{Authors' contributions}

LEA was the Principal Investigator who conceived and designed the study and supervised data collection as well as sample and data analysis; AO collected the samples; JA, AO, FKA and RAT performed molecular assays; LEA performed statistical analysis; LEA wrote the paper. All authors have read and approved the final manuscript.

\section{Author details}

${ }^{1}$ Immunology Department, Noguchi Memorial Institute for Medical Research, College of Health Sciences, University of Ghana, Legon, Accra, Ghana. ${ }^{2}$ Ghana Health Service, Ministry of Health, Accra, Ghana.

\section{Acknowledgements}

We would like all the volunteers and their parents/guardians for granting consent to be a part of this study. We would also like to thank Dr. T. Rajapandi of the MR4/ATCC and Dr. KA Kusi of the NMIMR for critically reading the manuscript and helping with the statistical analysis and AssessBIO for donating the CareStart $^{\mathrm{TM}}$ G6PD RDT kits used in this study.

\section{Competing interests}

The authors declare that they have no competing interests.

Availability of data and material

All data generated or analysed during this study are available from the corresponding author on reasonable request.

\section{Ethics approval and consent to participate}

The Institutional Review Board (IRB) of the Noguchi Memorial Institute for Medical Research (NMIMR) Granted ethical approval for the parent study. Parents and legal guardians of all the children gave written informed consent for use and future use of their children's samples prior to enrolment into the study.

\section{Funding}

This study was supported by University of Ghana research funding to LEA. The funders had no role in study design, data collection and analysis, decision to publish, or preparation of the manuscript.

Received: 19 February 2016 Accepted: 12 July 2016

Published online: 26 July 2016

References

1. WHO. World malaria report 2015: summary. Geneva: World Health Organization; 2016.

2. Ruwende C, Khoo SC, Snow RW, Yates SN, Kwiatkowski D, Gupta S, et al. Natural selection of hemi- and heterozygotes for G6PD deficiency in Africa by resistance to severe malaria. Nature. 1995;376:246-9.

3. Min-Oo G, Gros P. Erythrocyte variants and the nature of their malaria protective effect. Cell Microbiol. 2005;7:753-63.

4. Beutler E. G6PD: population genetics and clinical manifestations. Blood Rev. 1996;10:45-52.

5. Ruwende C, Hill A. Glucose-6-phosphate dehydrogenase deficiency and malaria. J Mol Med. 1998;76:581-8.

6. Agarwal A, Guindo A, Cissoko Y, Taylor JG, Coulibaly D, Koné A, et al. Hemoglobin $C$ associated with protection from severe malaria in the 
Dogon of Mali, a West African population with a low prevalence of hemoglobin S. Blood. 2000;96:2358-63.

7. Modiano D, Luoni G, Sirima BS, Simporé J, Verra F, Konaté A, et al. Haemoglobin C protects against clinical Plasmodium falciparum malaria. Nature. 2001:414:305-8.

8. Ayi K, Turrini F, Piga A, Arese P. Enhanced phagocytosis of ring-parasitized mutant erythrocytes: a common mechanism that may explain protection against falciparum malaria in sickle trait and beta-thalassemia trait. Blood. 2004;104:3364-71.

9. Ouattara AK, Bisseye C, Bazie BV, Diarra B, Compaore TR, Djigma F, et al. Glucose-6-phosphate dehydrogenase (G6PD) deficiency is associated with asymptomatic malaria in a rural community in Burkina Faso. Asian Pac J Trop Biomed. 2014;4:655-8.

10. Gouagna LC, Bancone G, Yao F, Yameogo B, Dabire KR, Costantini C, et al. Genetic variation in human HBB is associated with Plasmodium falciparum transmission. Nat Genet. 2010;42:328-31.

11. Courtin D, Milet J, Bertin G, Vafa M, Sarr JB, Watier L, et al. G6PD A-variant influences the antibody responses to Plasmodium falciparum MSP2. Infect Genet Evol. 2011;11:1287-92.

12. Shah SS, Diakite SA, Traore K, Diakite M, Kwiatkowski DP, Rockett KA, et al. A novel cytofluorometric assay for the detection and quantification of glucose-6-phosphate dehydrogenase deficiency. Sci Rep. 2012;2:299.

13. Adu-Gyasi D, Asante KP, Newton S, Dosoo D, Amoako S, Adjei G, et al. Evaluation of the diagnostic accuracy of CareStart G6PD deficiency rapid diagnostic test (RDT) in a malaria endemic area in Ghana, Africa. PLoS ONE. 2015;10:e0125796.

14. Kim S, Nguon C, Guillard B, Duong S, Chy S, Sum S, et al. Performance of the CareStart G6PD deficiency screening test, a point-of-care diagnostic for primaquine therapy screening. PLoS ONE. 2011;6:e28357.

15. Tantular IS, Iwai K, Lin K, Basuki S, Horie T, Htay HH, et al. Field trials of a rapid test for G6PD deficiency in combination with a rapid diagnosis of malaria. Trop Med Int Health. 1999;4:245-50.

16. von Fricken ME, Weppelmann TA, Eaton WT, Masse R, Beauderochars MV, Okech BA. Performance of the CareStart glucose-6-phosphate dehydrogenase (G6PD) rapid diagnostic test in Gressier, Haiti. Am J Trop Med Hyg. 2014;91:77-80.

17. Hsu J, Fink D, Langer E, Carter ML, Bengo D, Ndidde S, et al. PCR-based allelic discrimination for glucose-6-phosphate dehydrogenase (G6PD) deficiency in Ugandan umbilical cord blood. Pediatr Hematol Oncol. 2014:31:68-75.

18. Nadarajan V, Shanmugam H, Sthaneshwar P, Jayaranee S, Sultan KS, Ang $C$, et al. Modification to reporting of qualitative fluorescent spot test results improves detection of glucose-6-phosphate dehydrogenase (G6PD)-deficient heterozygote female newborns. Int J Lab Hematol. 2011;33:463-70.

19. Enevold A, Vestergaard LS, Lusingu J, Drakeley CJ, Lemnge MM, Theander TG, et al. Rapid screening for glucose-6-phosphate dehydrogenase deficiency and haemoglobin polymorphisms in Africa by a simple highthroughput SSOP-ELISA method. Malar J. 2005;4:61.

20. Mehta A, Mason PJ, Vulliamy TJ. Glucose-6-phosphate dehydrogenase deficiency. Baillieres Best Pract Res Clin Haematol. 2000;13:21-38.

21. Mason PJ, Bautista JM, Gilsanz F. G6PD deficiency: the genotype-phenotype association. Blood Rev. 2007;21:267-83.

22. Group WER. The safety and effectiveness of single dose primaquine as a $P$. falciparum gametocytocide. Geneva: World Health Organization; 2012

23. Kheng S, Muth S, Taylor WR, Tops N, Kosal K, Sothea K, et al. Tolerability and safety of weekly primaquine against relapse of Plasmodium vivax in Cambodians with glucose-6-phosphate dehydrogenase deficiency. BMC Med. 2015;13:203

24. White NJ, Qiao LG, Qi G, Luzzatto L. Rationale for recommending a lower dose of primaquine as a Plasmodium falciparum gametocytocide in populations where G6PD deficiency is common. Malar J. 2012;11:418.

25. Monteiro WM, Moura-Neto JP, Recht J, Bassat Q, Lacerda MV. Fatal primaquine-induced hemolysis in a patient with Plasmodium vivax malaria and G6PD A- variant in the Brazilian Amazon. Clin Infect Dis. 2016:62:1188

26. Group WER. Point-of-care G6PD testing to support safe use of primaquine for the tretment of vivax malaria. Geneva: World Health Organization; 2015. p. 1-25.
27. Government of Ghana GSS, Ghana Health Service, Accra, Ghana, UNICEF, UNFPA, Japan Official Development Assistance, USAID and ICF International, Calverton, Maryland, USA Ghana: Multiple Indicator Cluster Survey $2011 ; 2012$.

28. Statistical service Ghana. Population by region, district, age groups and sex. Accra; 2010.

29. Baidjoe A, Stone W, Ploemen I, Shagari S, Grignard L, Osoti V, et al. Combined DNA extraction and antibody elution from filter papers for the assessment of malaria transmission intensity in epidemiological studies. Malar J. 2013;12:272.

30. Carter N, Pamba A, Duparc S, Waitumbi JN. Frequency of glucose-6-phosphate dehydrogenase deficiency in malaria patients from six African countries enrolled in two randomized anti-malarial clinical trials. Malar J. 2011;10:241.

31. Manjurano A, Clark TG, Nadjm B, Mtove G, Wangai H, Sepulveda N, et al. Candidate human genetic polymorphisms and severe malaria in a Tanzanian population. PLoS ONE. 2012;7:e47463.

32. Owusu R, Asante KP, Mahama E, Awini E, Anyorigiya T, Dosoo D, et al. Glucose-6-phosphate dehydrogenase deficiency and haemoglobin drop after sulphadoxine-pyrimethamine use for intermittent preventive treatment of malaria during pregnancy in Ghana-a cohort study. PLoS ONE. 2015:10:e0136828.

33. Health GMf. Anti-malaria drug policy for Ghana. Accra; 2009.

34. Mockenhaupt FP, Mandelkow J, Till H, Ehrhardt S, Eggelte TA, Bienzle U. Reduced prevalence of Plasmodium falciparum infection and of concomitant anaemia in pregnant women with heterozygous G6PD deficiency. Trop Med Int Health. 2003:8:118-24.

35. Stephens JK, Ofori MF, Quakyi IA, Wilson ML, Akanmori BD. Prevalence of peripheral blood parasitaemia, anaemia and low birthweight among pregnant women in a suburban area in coastal Ghana. Pan Afr Med J. 2014;17(Suppl 1):3.

36. Mensah Bonsu D. Molecular basis of glucose-6-phosphate dehydrogenase deficiency in Cape Coast, Ghana. Kwame Nkrumah University of Science and Technology, Kumasi, Ghana, Department of Biochemistry and Biotechnology; 2013.

37. Amoako N, Asante KP, Adjei G, Awandare GA, Bimi L, Owusu-Agyei S. Associations between red cell polymorphisms and Plasmodium falciparum infection in the middle belt of Ghana. PLoS ONE. 2014:9:e112868.

38. Shah SS, Rockett KA, Jallow M, Sisay-Joof F, Bojang KA, Pinder M, et al. Heterogeneous alleles comprising G6PD deficiency trait in West Africa exert contrasting effects on two major clinical presentations of severe malaria. Malar J. 2016;15:13.

39. Uyoga S, Ndila CM, Macharia AW, Nyutu G, Shah S, Peshu N, et al. Glucose-6-phosphate dehydrogenase deficiency and the risk of malaria and other diseases in children in Kenya: a case-control and a cohort study. Lancet Haematol. 2015;2:e437-44.

40. Shah SS, Macharia A, Makale J, Uyoga S, Kivinen K, Craik R, et al. Genetic determinants of glucose-6-phosphate dehydrogenase activity in Kenya. BMC Med Genet. 2014;15:93.

41. Okebe J, Amambua-Ngwa A, Parr J, Nishimura S, Daswani M, Takem EN, et al. The prevalence of glucose-6-phosphate dehydrogenase deficiency in Gambian school children. Malar J. 2014;13:148.

42. Goto T, Monk M. Regulation of X-chromosome inactivation in development in mice and humans. Microbiol Mol Biol Rev. 1998;62:362-78.

43. Barakat TS, Gribnau J. X chromosome inactivation in the cycle of life Development. 2012;139:2085-9.

44. Espino FE, Bibit JA, Sornillo JB, Tan A, von Seidlein L, Ley B. Comparison of three screening test kits for G6PD enzyme deficiency: implications for its use in the radical cure of vivax malaria in remote and resource-poor areas in the Philippines. PLoS ONE. 2016;11:e0148172.

45. Magon AM, Leipzig RM, Zannoni VG, Brewer GJ. Interactions of glucose6-phosphate dehydrogenase deficiency with drug acetylation and hydroxylation reactions. J Lab Clin Med. 1981;97:764-70.

46. Cassimos C, Malaka-Zafiriu K, Tsiures J. Urinary D-glucaric acid excretion in normal and G-6-PD deficient children. J Pediatr. 1974;84:871-2.

47. Heymann A, Cohen Y, Chodick G. Glucose-6-phosphate dehydrogenase deficiency and type 2 diabetes. Diabetes Care. 2012;35:e58.

48. Beutler E. G6PD deficiency. Blood. 1994;84:3613-36. 